\title{
A CROSS-CULTURAL COMPARISON OF PREFERENCES FOR LANDSCAPE STYLES AND LANDSCAPE ELEMENTS
}

BYOUNG-E YANG is Professor of Landscape Architecture, Graduate School of Environmental Studies at Seoul National University, Seoul, Korea. He received a Ph.D. in Landscape Architecture from the University of Michigan. His current research interests focus on landscape preference, comparison of landscape styles and landscape assessment.

TERRY J. BROWN is Associate Professor of Landscape Architecture, School of Natural Resources, University of Michigan. His research concerns the interrelationship of landscape design and landscape planning processes, the use of geographic information systems in the land use planning process, and the use of microcomputers in landscape architecture.

ABSTRACT: Visual preferences for various landscapes have been of long-standing interest to researchers. However, the direct relationship of landscape style with preference as well as cross-cultural comparison of preferences between Western and non-Western groups has received little attention. Three aspects of this problem are addressed in this study. First, the characteristics of preferences for three landscape styles, namely, Korean, Japanese, and Western are presented. Second, characteristics of preferences for three landscape elements-water, vegetation, and rock-are analyzed. Finally, a photo-questionnaire was used to make cross-cultural comparisons of preferences between a Korean group and a Western tourist group. It was found that regardless of cultural differences, both Japanese landscape style and the landscape element water were most preferred by both Koreans and Western tourists. For the Koreans, Western landscape style was more preferred than their own Korean landscape style whereas Korean landscape style is more preferred by Western tourists. The results point to both landscape style and landscape elements as the influencing factors on landscape preference, regardless of cultural differences, and there are both differences and similarities in preferences between Korean and Western groups.

In recent years a substantial amount of literature has developed concerning the assessment of landscape quality. Analysis techniques obtaining landscape preferences have been widely 
used in many of these studies as a means of obtaining responses from the public to the landscape under study. Of these assessments, none have examined the direct relationship of landscape style with preference. On the other hand, a large number of studies have dealt with the relationships of preference for water and vegetation, none have studied preference for rock. Almost unanimously, studies have shown that water is one of the most powerful elements in enhancing preferences (e.g., Brush \& Shafer, 1975; Civco, 1979; Kaplan \& Kaplan, 1982; Palmer, 1978; Penning-Roswell, 1979; Shafer, Hamilton, \& Schmidt, 1969; Ulrich, 1981; Zube, Pitt, \& Anderson, 1975). In addition, numerous studies concerning preference for landscapes have also reported that trees or vegetation play a special role as a specific content in enhancing preference (e.g., Balling \& Falk, 1982; Gallagher, 1977; Herzog, Kaplan, \& Kaplan, 1982; R. Kaplan, 1983; Kaplan, Kaplan, \& Wendt, 1972; Schroeder \& Daniel, 1981; Thayer \& Atwood, 1978; Ulrich, 1981; Vining, Daniel, \& Schroeder, 1984).

Cross-cultural studies involving landscape preference have raised the question to what degree cultural factors influence preference. Of these studies, there are a number of different perspectives concerning cultural influences. One group has shown relatively high agreement when cultures are fairly similar (Zube, 1984), such as between Scots and Americans (Shafer \& Toobey, 1973) and Australians and Americans (Zube \& Mills, 1976). Ulrich reported similar findings with high rank-order correlation (.88) between Swedish and American ratings (Ulrich, 1977). Additionally, even if cultures are dissimilar, broad consistencies across cultures in responsiveness to visual environments are suggested by results from some semantic evaluation procedures. A study by Kwok (1979) employed Küller's semantic scales with samples of architectural and landscape slides to obtain data from Chinese students in Singapore and from middle-income British professionals in London. Semantic factors identified for both groups were nearly the same as Küller's factors for Swedish subjects (Küller, 1972), which would indicate similarity across different cultures. Likewise, Berlyne, Robbins, and Thompson (1974) found similar factors from broad seman- 
tic evaluations of abstract visual arrays between Canadian university students and a diverse sample in Uganda.

By contrast, another group of studies presents evidence that culture is a preeminent determinant of preference (e.g., Lowenthal, 1968; Sonnenfeld, 1967; Tuan, 1973; Zube \& Pitt, 1981). Differences in perceived landscape values have been found when there were significant differences between cultures. Sonnenfeld (1967) discovered strong differences in preferences between Eskimos and Americans. Zube and Pitt (1981) reported that there were relatively low correlations in scenic quality ratings between West Indians and Americans.

A third group of studies have shown that both similarities and differences in landscape preferences were found across cultures in a project by Kaplan and Herbert (1987). They reported that preference ratings showed surprisingly high agreement between Australian and American groups whereas some striking differences were identified in perceptual categories between participants and some of the larger differences were found between subcultural groups within the Australian samples. Tips and Savasdisara (1968) found that there is agreement over the basic preferences, but, nevertheless, there are smaller differences in the response among Asian samples (samples from Nepal, Thailand, Sri Lanka, Republic of China, Bangladesh, and Indonesia) including a group of Western tourists.

Despite an abundance of literature concerning landscape preferences, only a few studies (Berlyne et al., 1974; Kwok, 1979; Nasar, 1984; Tips \& Savasdisara, 1986) have dealt with the comparison of landscape preferences between Western and non-Western groups. No study was found that compared landscape preferences between Korean and Western groups as this article will present. The primary aim of this study was to compare the visual preferences for landscapes between Korean and Western groups with particular emphasis on the preferences for landscape style as well as the elements comprising the landscape.

A substantial body of knowledge concerning environmental preference, which has been previously discussed, is based on the use of photographs of the environment. Several studies 
have revealed that preference ratings obtained by using blackand-white photographs create no problem in obtaining people's reaction to such scenes (R. Kaplan, 1979a, 1979b; Hammitt, 1978; Peterson \& Neumann, 1969; Shafer et al., 1969). The approach to this study involved a photo-questionnaire in obtaining preference ratings of the landscape scenes.

The landscape styles of China, Japan, and Korea have many similarities as the three countries have common cultural backgrounds and Chinese culture has influenced Korean and Japanese culture, but these Oriental styles also have some distinct differences. Based on a review of the literature on Oriental landscape styles (Chung, 1982; Graham, 1938; Harada, 1956; Hayakawa, 1973; Oldham, 1980; Tamura, 1935; Thacker, 1979; Tung, 1940; Yoon, 1983), it was suggested that some differences were found among the landscape styles common to China, Japan, and Korea; these differences can be described in terms of (a) layout of space, (b) use of plants, (c) use of sculptural elements/stone, (d) use of water, and (e) use of vista. These sources describe Chinese gardens as usually divided into corridors and courts in which buildings dominate; in Japanese gardens, there is no evident example of the division of the space within the gardens. On the other hand, traditional Korean gardens are characterized by the vertical division instead of the horizontal division of garden space (Yoon, 1983). In both Korean and Chinese landscape styles, we find neither trimmed hedges in straight lines, nor any appearance of artifice in plant form (Tung, 1940). Shaping and trimming of shrubs and trees is however, an integral part of the Japanese landscape style. The rocks favored in the Chinese garden are ancient, water-eroded masses of limestone of weird and fantastic shapes (Hyams, 1971). Sophisticated techniques of stone arrangement are widely used in the Japanese landscape style, and there are three generic types of stone use in a Korean garden. Water in the Japanese garden is used with much wider diversity than in Chinese or Korean gardens. Uniquely, in Japanese gardens, water is suggested or represented symbolically when not actually used (Tamura, 1935). In contrast to the curvilinear shapes in both Japanese and Chinese gardens, the shape of the basin holding 
water in the Korean garden is most often rectangular whether a lake or pool (Chung, 1982). Borrowed scenery is employed in both the Chinese and Japanese landscape styles but it is not a part of the Korean landscape style (Yoon, 1983).

\section{METHODS}

\section{PHOTO SELECTION}

Because the preference ratings were based on photos in a photo-questionnaire, the content and quality of the photos are most important. Every effort was made to take photos that best represent the characteristics of three different landscape styles, Korean, Japanese, and Western. In order to investigate the influences of landscape elements on preferences, four landscape qualities or elements were selected for inclusion in the photos: (a) the layout of space, (b) the use of landscape plants, (c) the use of stones and rocks or sculptural elements (herein referred to as "rock"), and (d) the use of water.

Forty black-and-white photos included in the photo-questionnaire were selected according to the criteria shown in Table 1. The photos representing both Japanese style layout of space and the use of stone/rocks in the Western landscape style were not included because good examples under those categories were not found in Korea. Black-and-white photos were used to control the color effect of the landscape. Although most of the photos were taken in Seoul, several photos of Japanese gardens were taken in Pusan and Kyongju, Korea, because of the availability of good examples. All scenes were to be shown at eye level to depict landscapes which people encounter during their normal experiences with the environment. Scenes were taken between 10:00 a.m. and 4:00 p.m. with minimal cloud, fog, and haze during the growth seasons of 1984-1986; a $35 \mathrm{~mm}$ lens was used to take the photos showing the layout of space and a $55 \mathrm{~mm}$ lens for the other three characteristics.

In order to verify the kinds of landscape styles and elements in the photographs, a panel of experts, which consisted of 10 
TABLE 1

Number of Photos Selected at the Final Stage

\begin{tabular}{lcccc}
\hline & \multicolumn{4}{c}{ Landscape Style } \\
\cline { 2 - 5 } Landscape Characteristics (Elements) & Korean & Japanese & Western & Total \\
\hline Layout of space & 4 & 0 & 4 & 8 \\
Use of plants & 4 & 4 & 4 & 12 \\
Use of stones and rocks & 4 & 4 & 0 & 8 \\
Use of water & 4 & 4 & 4 & 12 \\
Total & 16 & 12 & 12 & 40 \\
\hline
\end{tabular}

Korean and 5 American professors and experts in landscape architecture, was employed. One hundred twenty-four photos were distributed to 10 Korean experts in order to gain their professional judgments about how well the photos represent the characteristics of different landscape styles. They were requested to rate how well each photo represented the respective characteristics using a 5-point scale. Based on the ratings by Korean experts, 45 photos were tentatively selected for the photo-questionnaire. At the next stage, the panel of experts including 5 American and 10 Korean professors reviewed these 45 photos and finally selected 40 photos to be used for the photo-questionnaire.

\section{QUESTIONNAIRE DEVELOPMENT}

The photos printed in the photo-questionnaire were arranged in two orders. The initial order was made by random assignment of photos based on landscape style and elements. The second sequence was the reverse order to eliminate possible influences or biases created by the order of photos. Respondents were asked to indicate their degree of preference for a scene, and their degree of familiarity with the scene on a Likert-type scale, from 1 to 5 . For the Korean sample, the questionnaire was written in Korean and for the Western sample, it was written in English. Accompanying the photo-questionnaire was a set of verbal questions designed to investigate the respondent's social status and previous experiences. 


\section{RESPONDENTS AND SAMPLING PROCEDURE}

The study was carried out in Seoul, the capital and largest city of Korea. It has a population of 9,650,000 (as of 1985), which is $24.8 \%$ of Korea's total population. The sample included three distinct groups: (a) citizens of Seoul, (b) college students of Seoul National University, and (c) Western tourists in Seoul. The respondents for the study were limited to adults over the age of 18. The sample selection of the citizen group was achieved through a multistage random sampling process. In the case of the college students of Seoul National University, the sample included two distinct groups: (a) students majoring in landscape architecture and (b) students majoring in academic fields other than landscape architecture. The selection of landscape architecture students was made randomly from the students in the landscape architecture program at Seoul National University. Nonmajors were selected randomly from the students using the Central Library of Seoul National University. Sample selection of Western tourists were made randomly from the visitors at the historical palaces in Seoul. Western tourists chosen for the survey were limited to Europeans and Americans, including Canadians and South Americans, who were at least 18 years old.

The survey was conducted during November, 1986. Twentysix college students from Seoul National University were employed to conduct the survey. For the survey of citizens, the photo-questionnaire was delivered to the selected household, was left with the respondent, and then was picked up at an agreed on time. When the employed student returned to the respondent's home again to pick up the completed questionnaire, he or she reviewed the questionnaire and requested the respondent complete any unfinished items. Questionnaires were distributed to 432 Korean citizens and 415 questionnaires were returned from them ( $96 \%$ return rate). English major students were employed the survey of Western tourists. During one weekday and on Sunday, they randomly selected respondents from the visitors to three major historic palaces: (a) Changdok Palace, (b) Kyongbok Palace, and (c) Doksu Palace in Seoul. One hundred ten Western tourist were requested to respond to 
the questionnaire while the employed student waited in order to insure that the questionnaire would be returned $(100 \%$ return rate). Of nonlandscape architecture majors of Seoul National University, the questionnaires were distributed randomly to the users of the Central Library at Seoul National University and picked up after 1 hour by the employed students. The survey of the landscape architecture student group was conducted at the Department of Landscape Architecture, Seoul National University. One hundred forty Korean students including both nonlandscape architecture majors and landscape architecture majors were requested to respond to the questionnaire and 135 questionnaires were returned ( $96 \%$ return rate).

\section{RESULTS AND DISCUSSION}

This study employed a three-factored design, with three landscape styles, four landscape elements, and two culturally different samples. Unfortunately, however, the fact that two combinations of style and elements are not present makes it an incomplete design and makes it difficult to examine the study as a whole. In particular, it becomes impossible to look at the interaction effects as a whole. However, main effects of landscape style and element between Korean and Western samples were reviewed by using a three-way analysis of variance (ANOVA). Further, bivariate interaction effects were also analyzed by conducting a series of two-way ANOVAs that look at the interaction of landscape elements and sample separately for each style and the interaction of style and sample separately for each element.

\section{CHARACTERISTICS OF KOREAN PREFERENCES}

\section{Characteristics of Landscape Preference Patterns}

Forty landscape scenes were rated by 550 Korean respondents. The overall mean for the 40 photographs was 2.84 (on a 5-point scale) with a range from a low of 1.98 to a high of 3.89 . 
The scores were skewed slightly toward the lower end of the scale, indicating a somewhat negative response to the landscape scenes in the photos.

It is not practical to consider each of the 40 photographs individually, but it is worthwhile to examine the most and the least preferred scenes. The six most preferred landscape scenes (with the mean score over 3.5) are shown in Figure 1. Examination of these scenes shows the dominance of water (4 scenes) and Japanese landscape style (3 scenes). In Western cultures, water has been shown to be highly preferred (Kaplan \& Kaplan, 1982). A closer examination of the most preferred water scenes shows the importance of reflections. All four scenes are surrounded by vegetation and show reflections of the trees on the water. The preferred scenes (except photo 8) also all contain open and long views. Further, all but two Korean scenes are characterized by a natural form of landscape elements and informal layout.

The six least preferred landscape scenes are shown in Figure 2. These scenes appear to be more uniform in general appearance than the most preferred scenes. An examination of these photos indicates that the common characteristics are the presence of rock/stone and the Korean landscape style. Other commonalities include sparse or no vegetation, rectangular shape of elements, and blocked view, which are contrary to the characteristics of the highly preferred landscape scenes.

\section{Relationship of Landscape Preference to Landscape Style}

The photo-questionnaire included scenes representing three different landscape styles: Korean, Japanese, and Western. The mean preference scores for the three landscape styles are significantly different $(F=4.01, p<.05)$ with the Japanese most preferred (mean 3.08), the Western style in the middle (mean 2.89), and Korean (mean 2.63) least preferred. It is interesting to find that the Western landscape style is more preferred by Koreans than Korean landscape style, which is their own traditional landscape style. 

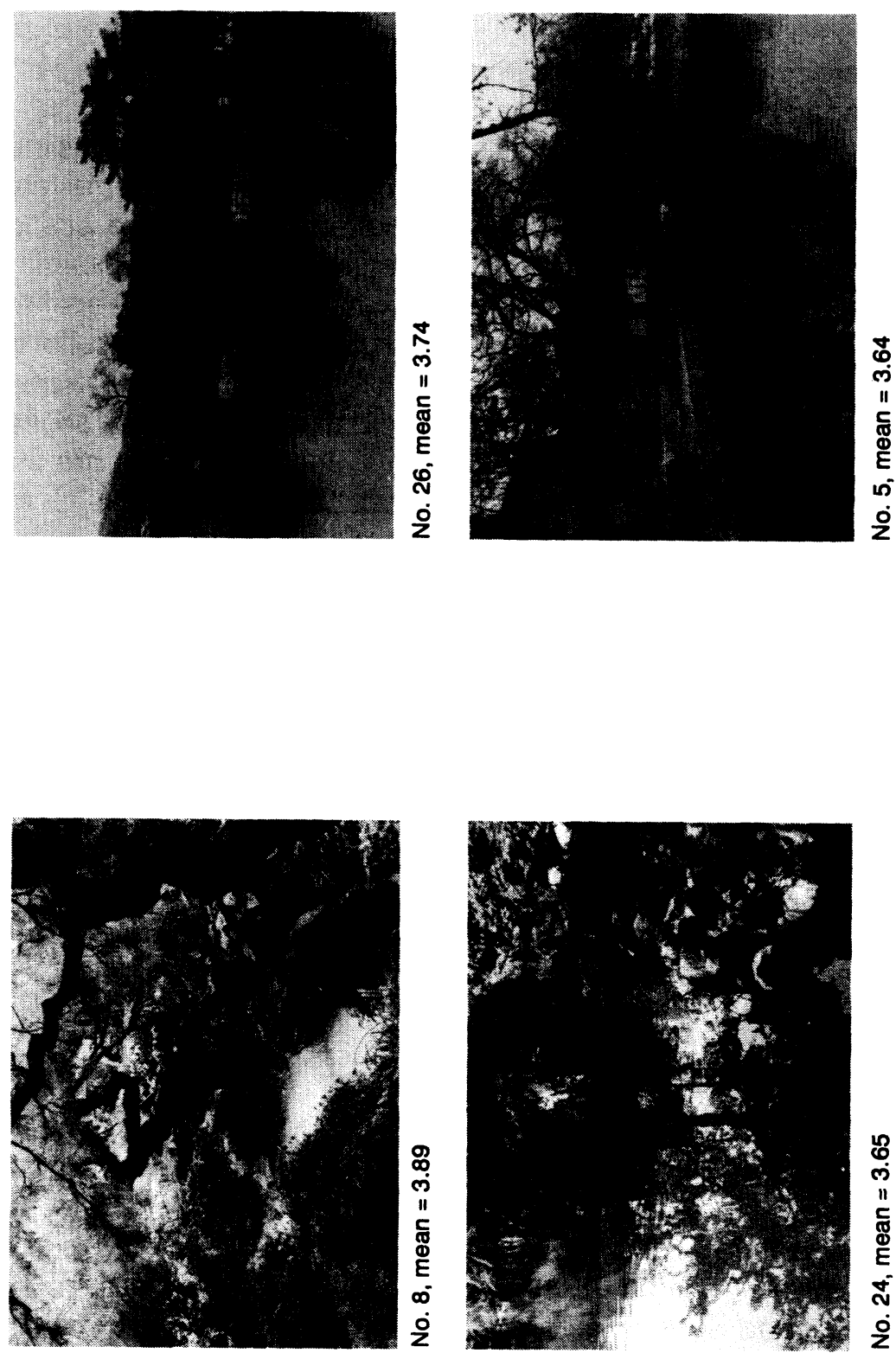


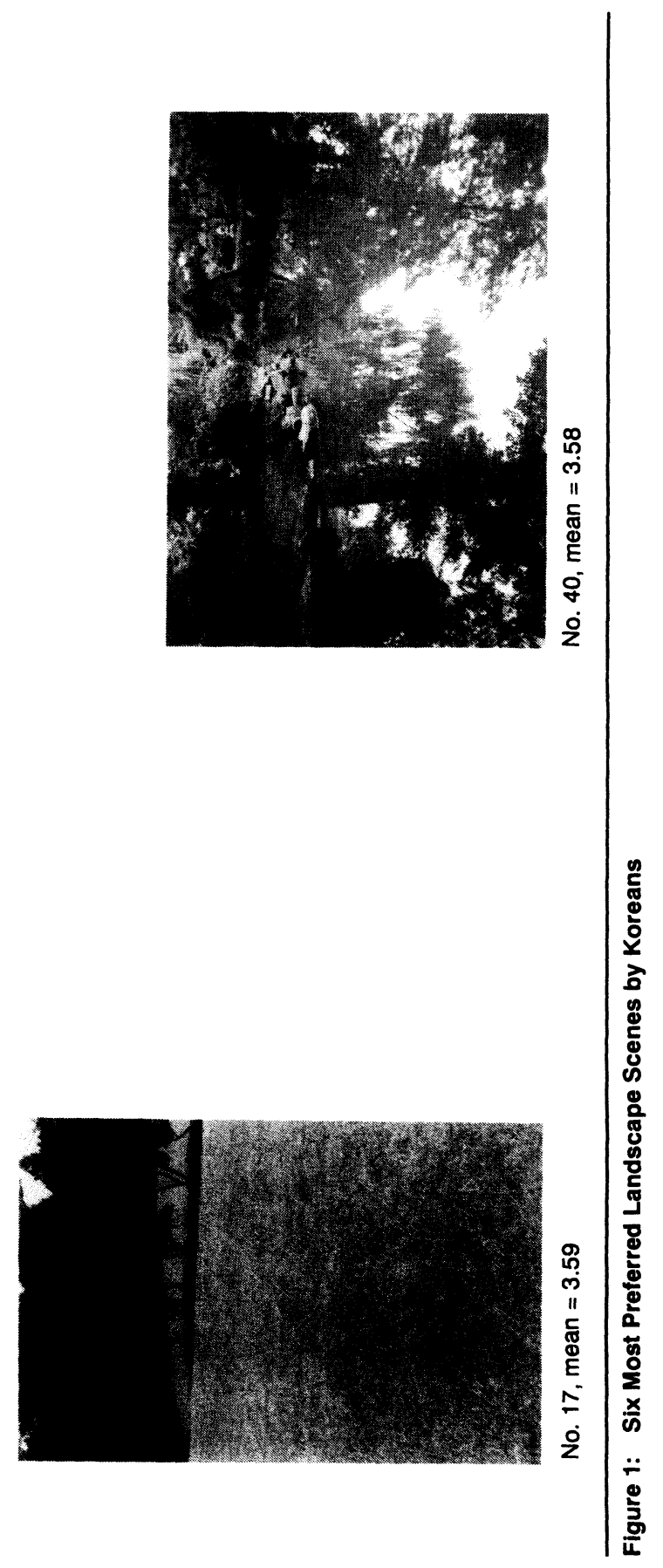



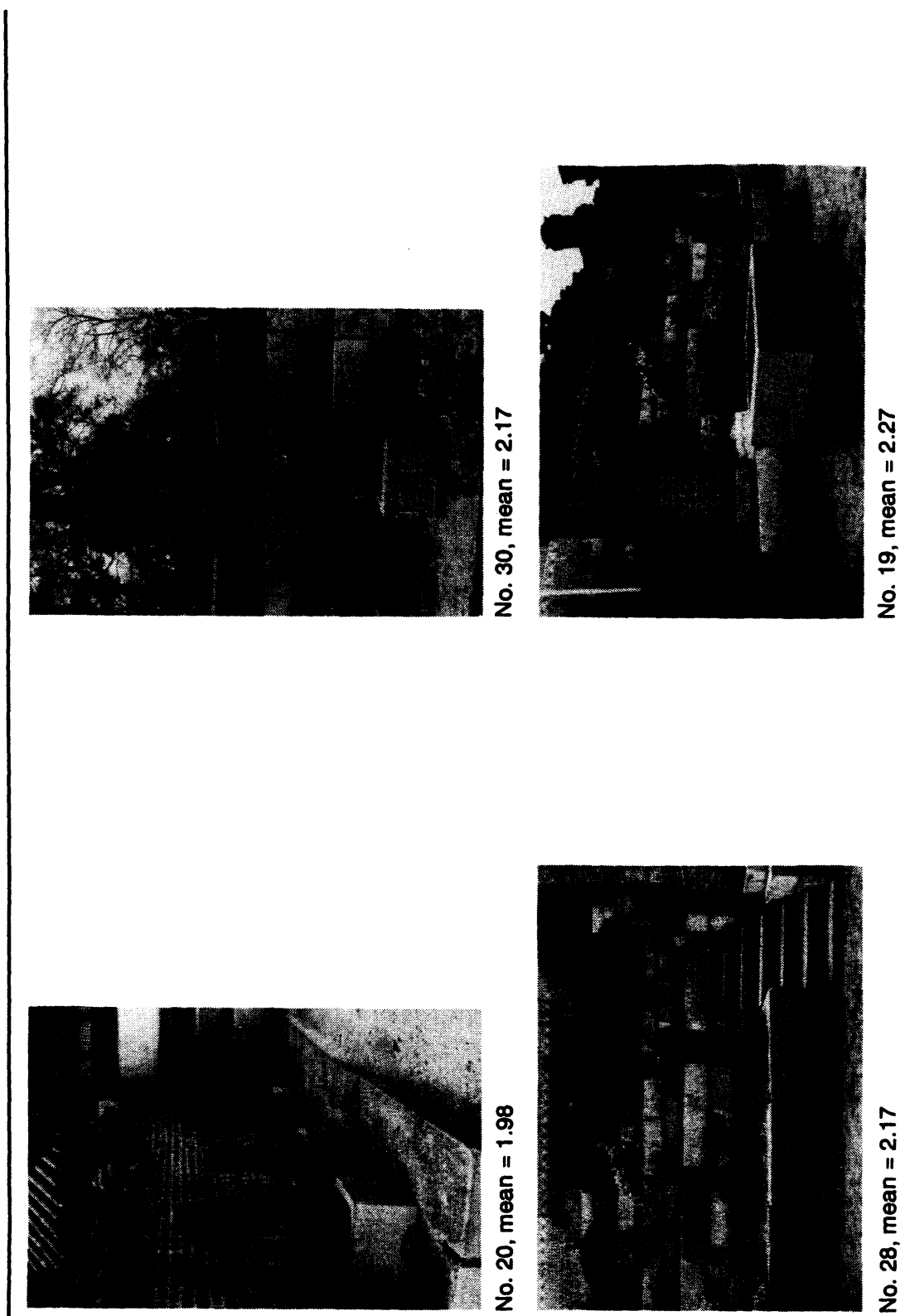


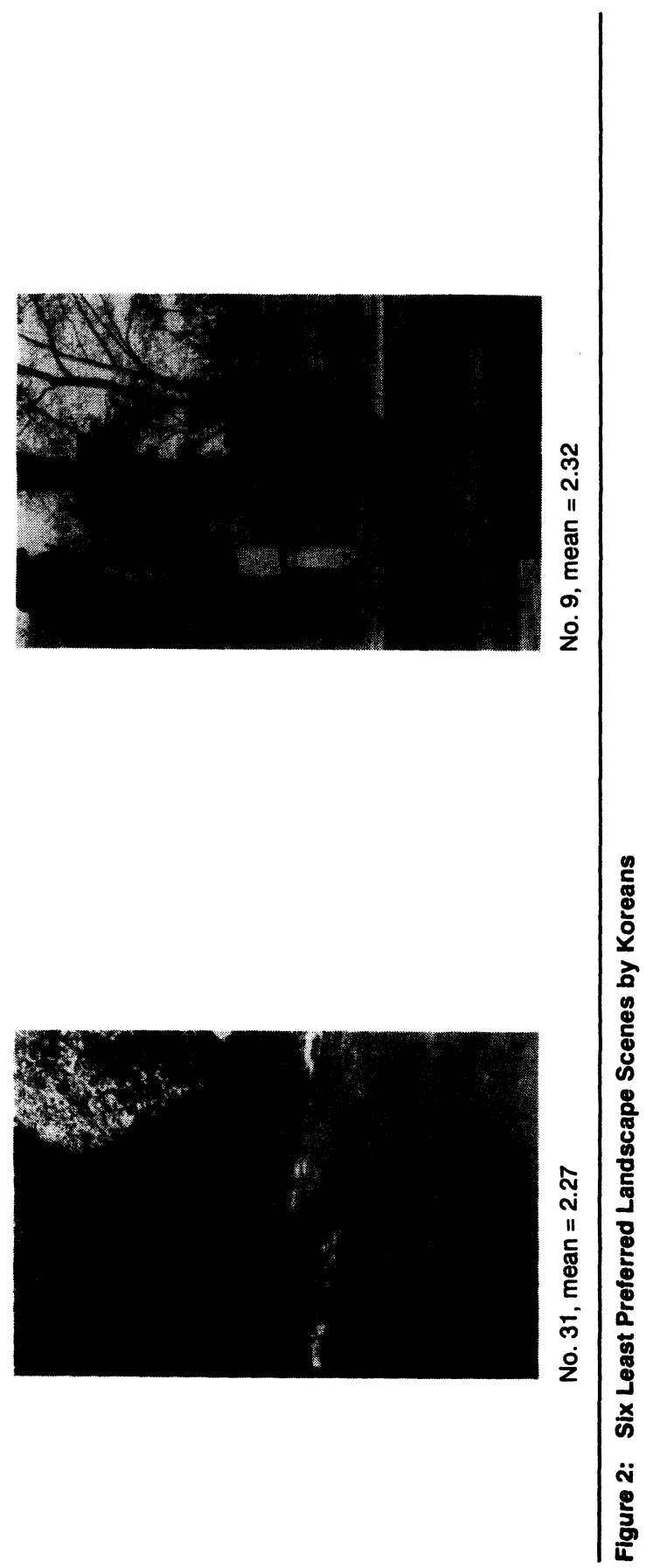


Further comparisons of preferences for landscape style between Korean subgroups show the citizens' preferences for Western landscape style (mean 2.95) was higher than students' preferences (mean 2.70). When the citizen group was compared to the student group of the same age (under 30 years old), students' preference for Japanese landscape style was higher than citizens' preference. There were no differences in preferences for other landscape styles between these groups.

\section{Relationship of Landscape Preferences to Landscape Element}

Preferences for three major landscape elements-water, vegetation, and rock-were significantly different $(F=7.89, p<$ .001 ) with water the most preferred element (mean 3.18), vegetation next (mean 2.97), and rock (mean 2.42 ) the least preferred element by Korean people.

Even though water received the highest mean score, the preferences for water scenes ranged from 2.35 to 3.74 suggesting that not all types of water equally enhance the Korean preferences. Although the existence of water in the landscape plays a powerful role as a contributing element to enhancing the preferences, there are differences in preference within the Korean people for water depending on the type and its relationship with other landscape elements. Mean preference scores for rock ranged from 1.98 to 2.88 , indicating that all these scenes were relatively low in preference. A close examination of the preference scores for rock indicates that the relationship of rock with other soft landscape material and the shape of the rock influence preferences.

Relative to other landscape elements, vegetation had the widest range of preference mean scores, from 2.44 to 3.89 . This infers that the preferences for vegetation differ depending on the form, type, and the relationship of vegetation to other landscape elements. Further analysis of the vegetation photos suggested that reflecting water or dense vegetation was highly preferred regardless of landscape style. Among the photos representing Western style, the photos with geometrical or symmetrical layout of vegetation are less preferred by Korean 
TABLE 2

Comparison of Preference Mean Score by Landscape Style and Landscape Element Between Korean and Western Samples

\begin{tabular}{|c|c|c|c|c|c|c|}
\hline \multirow[b]{2}{*}{$\begin{array}{l}\text { Landscape } \\
\text { Element }\end{array}$} & \multirow[b]{2}{*}{ Sample } & \multicolumn{3}{|c|}{ Landscape Style } & \multicolumn{2}{|c|}{$\begin{array}{l}\text { Landscape } \\
\text { Element }\end{array}$} \\
\hline & & Korean & Japanese & Western & $\begin{array}{l}\text { Korean } \\
\text { Sample }\end{array}$ & $\begin{array}{l}\text { Western } \\
\text { Sample }\end{array}$ \\
\hline Water & $\begin{array}{l}\text { Korean } \\
\text { Western }\end{array}$ & $\begin{array}{l}3.16 \\
3.47\end{array}$ & $\begin{array}{l}3.47 \\
4.06\end{array}$ & $\begin{array}{l}2.91 \\
3.18\end{array}$ & 3.18 & 3.57 \\
\hline Rock & $\begin{array}{l}\text { Korean } \\
\text { Western }\end{array}$ & $\begin{array}{l}2.23 \\
2.87\end{array}$ & $\begin{array}{l}2.62 \\
3.21\end{array}$ & - & 2.42 & 3.04 \\
\hline Vegetation & $\begin{array}{l}\text { Korean } \\
\text { Western }\end{array}$ & $\begin{array}{l}2.66 \\
3.13\end{array}$ & $\begin{array}{l}3.16 \\
3.75\end{array}$ & $\begin{array}{l}3.09 \\
3.16\end{array}$ & 2.97 & 3.35 \\
\hline Layout of space & $\begin{array}{l}\text { Korean } \\
\text { Western }\end{array}$ & $\begin{array}{l}2.48 \\
3.43\end{array}$ & - & $\begin{array}{l}2.67 \\
3.09\end{array}$ & 2.58 & 3.26 \\
\hline Landscape style & $\begin{array}{l}\text { Korean } \\
\text { Western }\end{array}$ & $\begin{array}{l}2.63 \\
3.23\end{array}$ & $\begin{array}{l}3.08 \\
3.67\end{array}$ & $\begin{array}{l}2.89 \\
3.14\end{array}$ & & \\
\hline
\end{tabular}

people than the photos with natural layout of vegetation. In the case of Korean landscape style, a blocked view caused by functional rock or wall without vegetation is less preferred than the blocked view by functional rock or wall with vegetation. Comparisons of preferences for landscape element between subgroups indicate that there were no significant differences in preferences for landscape elements between citizens and students.

\section{Relationship of Landscape Preferences to} Landscape Style and Landscape Elements

The landscape elements were selected to be representative of each of the three landscape styles and the relationship of these two factors was examined. Table 2 shows these means for the Korean sample. A series of two-way ANOVAs suggested that there are no significant interaction effects $(F=.937$, significance of $F=.456$ ) between two factors, landscape style and elements.

These results indicate that for the Korean sample, a Japanese-style water element was the most preferred combination. 
Although Japanese style is preferred for other elements as well, especially vegetation, Korean-style water elements received the same level of preference. Korean-style rock, however, was least preferred of all the combinations, with Japanese-style rocks and Korean-style vegetation the next least preferred (see Table 2).

When one examines the photos representing Japanese water and the combinations with the highest preference score, one finds several common characteristics: (a) the water reflects the shadows of trees, (b) the water is surrounded by dense vegetation, (c) the water's edge has a natural or nongeometric form, (d) water occupies the majority of the scene, and (e) relatively open and long views are created over the water in the preferred scene. In contrast, the commonalities found in the Korean rock photos which were the least preferred combinations are: (a) the rock stands alone or is mixed with sparse vegetation, (b) rock exists as a background wall or functional rock, (c) two or more rocks are scattered in the scene, (d) natural forms of rocks are juxtaposed with rectangular forms of rocks, and (e) natural rocks stand erect in the container made by rock.

\section{CHARACTERISTICS OF WESTERN PREFERENCES}

\section{Characteristics of Landscape Preference Patterns}

The same 40 landscape scenes the Korean samples rated were also rated by 106 Western respondents (four respondents were not included in the analysis due to unfinished responses). The overall mean for the 40 photographs was 3.34 on a 5-point scale, with a range from 2.68 to 4.48 . The scores are skewed toward the higher end of the scale, indicating a positive response to the landscape scenes in the photos in contrast to the Korean responses.

In order to find out the characteristics of landscape preferences of Western tourists and compare them with those of Koreans, we again investigate the most and least preferred scenes. Figure 3 shows the six landscape scenes most preferred by Western tourists. Four of these (photos 8, 24, 40, and 
5) turn out to be the same photos as in the Korean sample. Looking closely at the six most preferred landscape scenes, we can discover several common characteristics: (a) all of the highly preferred water scenes are surrounded by vegetation and contain a large amount of tree reflections, (b) two thirds of the photos have open and long views except photos 8 and 12, and (c) four Japanese-style photos $(8,24,40$, and 39$)$ are characterized by naturalness and informality in terms of the layout of the major components in the landscape.

Figure 4 shows the six landscape scenes least preferred by Western tourists. Three photos (photos 20, 31, and 30) were also among the least preferred for Koreans. Taken as a group, however, the Westerner's low-preference scenes reflect the following characteristics: Unlike the least preferred photos by Korean people, these scenes appear to be multiform in general appearance. Half of them contain an element of rock and represent Korean landscape style. Lack of vegetation is another commonality found in the landscape scenes. Several photos (such as photos $32,30,31$, and 20) also have blocked views in contrast to the most preferred landscape scenes. In addition, rectangular or linear forms is one of the most common characteristics among the least preferred photos. In view of the common characteristics found in the most and the least preferred landscape scenes, the following conclusions can be obtained from the Western tourists: (a) they also prefer water scenes surrounded by vegetation and with reflections of this vegetation on the water, (b) Japanese landscape style is more preferred than any of the two other landscape styles, (c) open and long views are also more preferred than blocked views, and (d) Western tourists prefer naturalness and informality to formality in terms of the layout and major in the landscape.

\section{Relationship of Landscape Preferences to Landscape Style}

For Western tourists, the styles were significantly different $(F=10.74, p<.001)$ in preferences with the Japanese-style landscapes (3.67) preferred to either of the other styles, whereas 

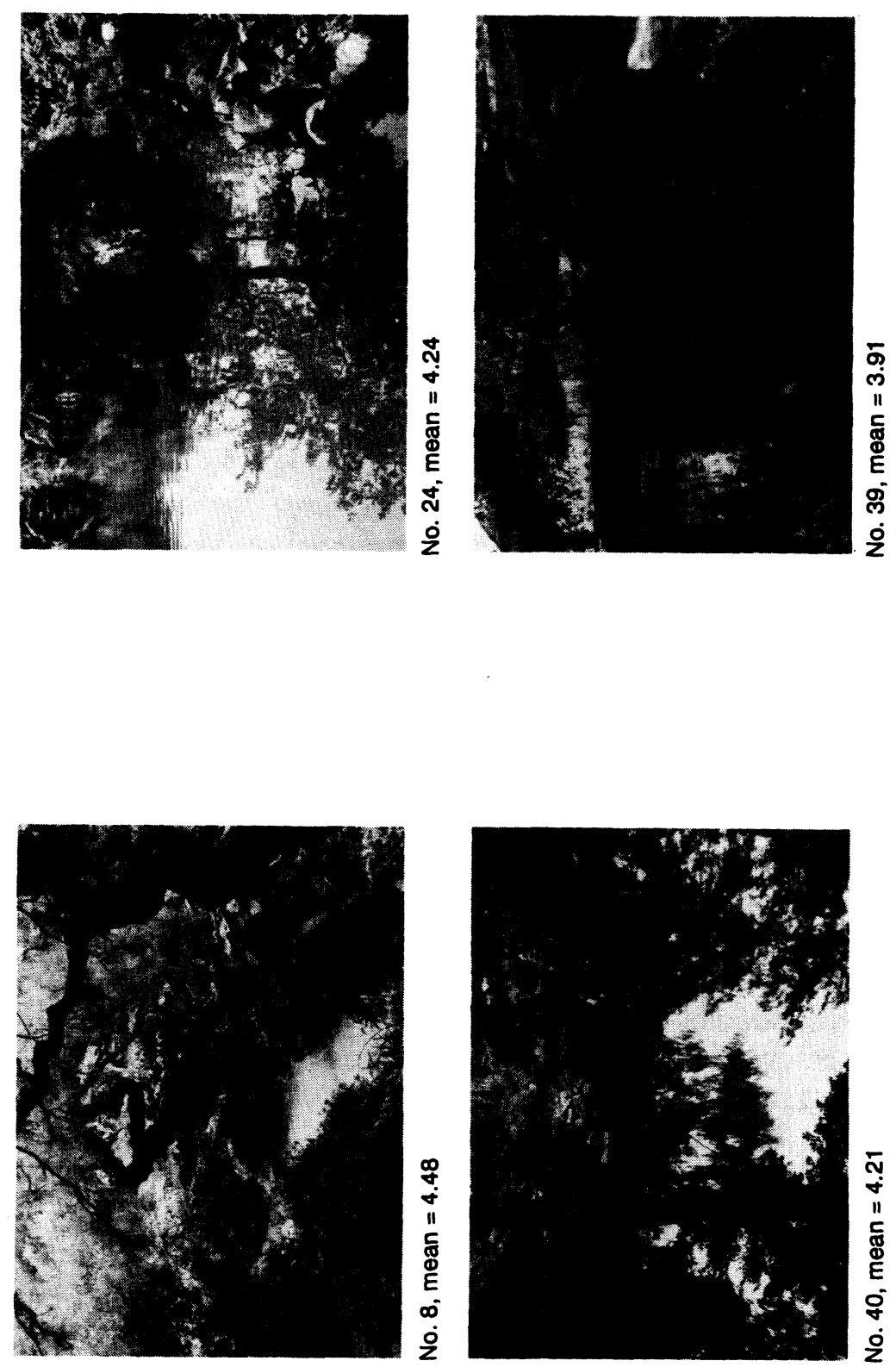


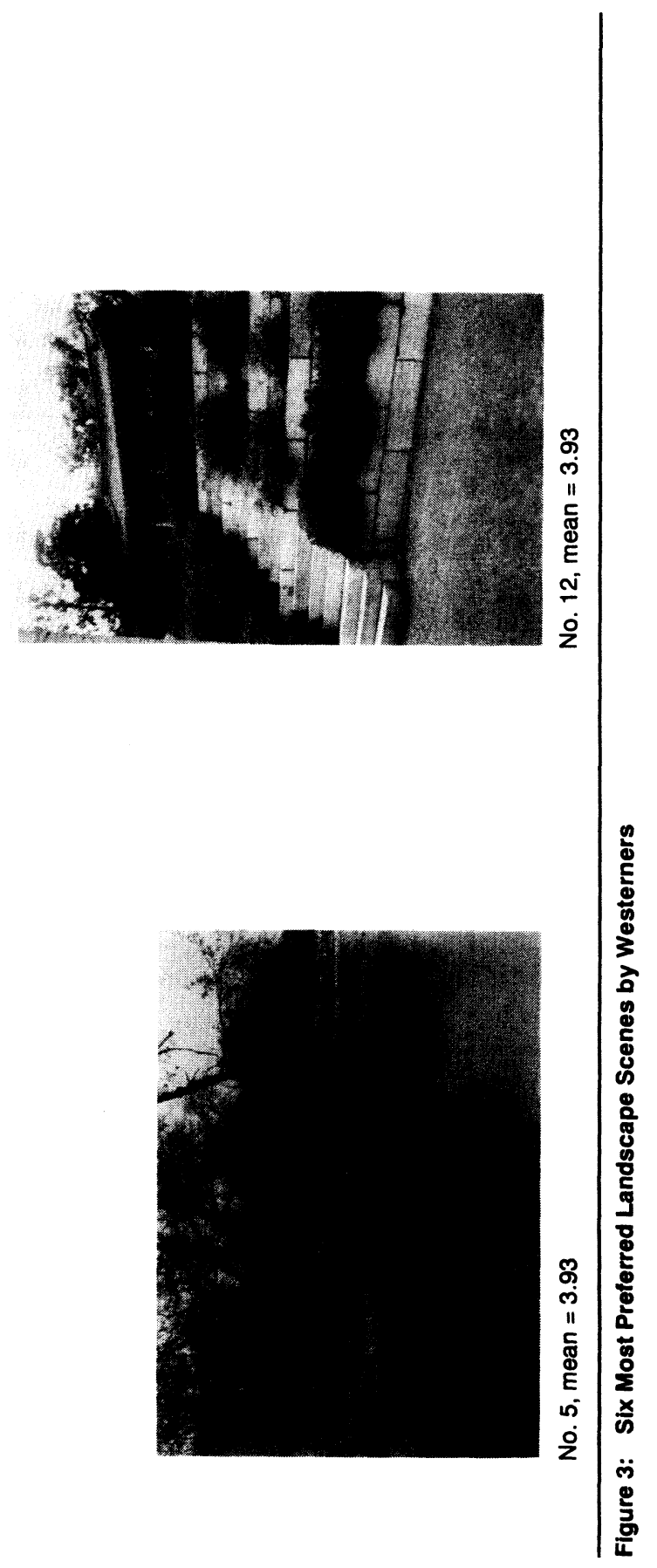



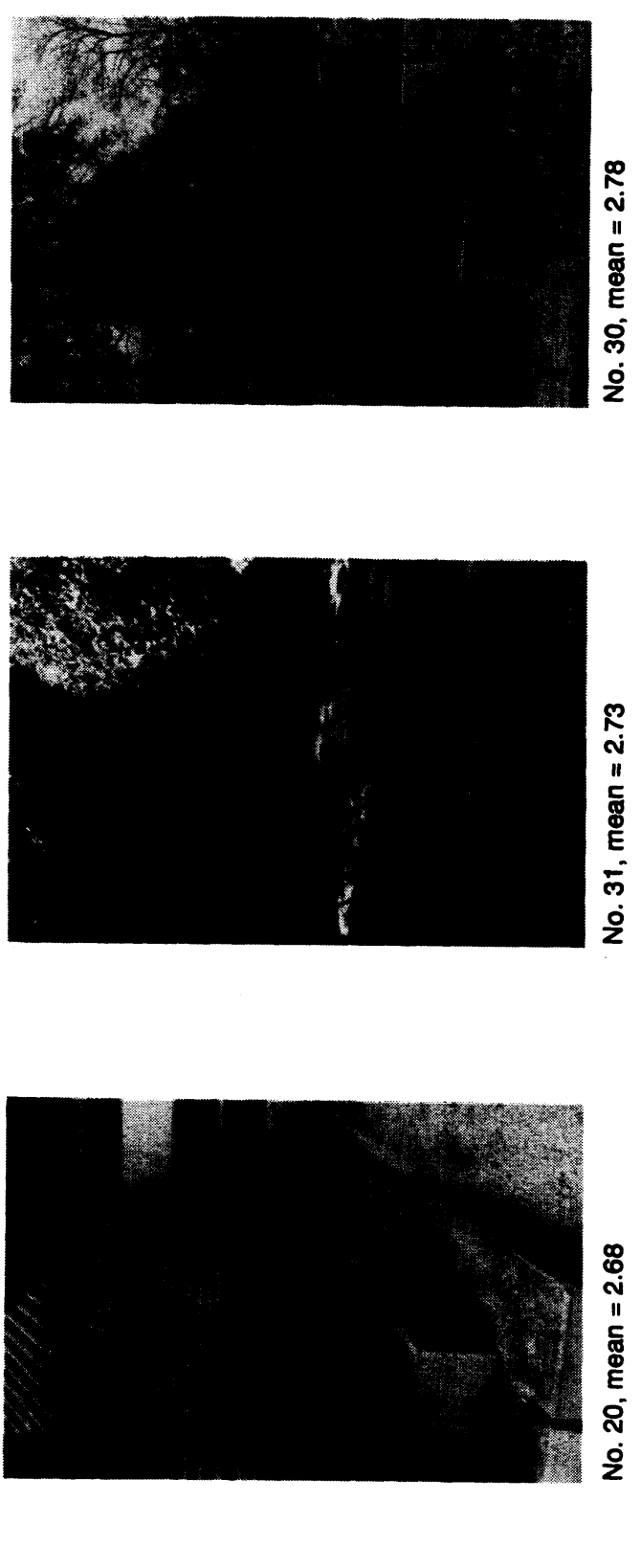


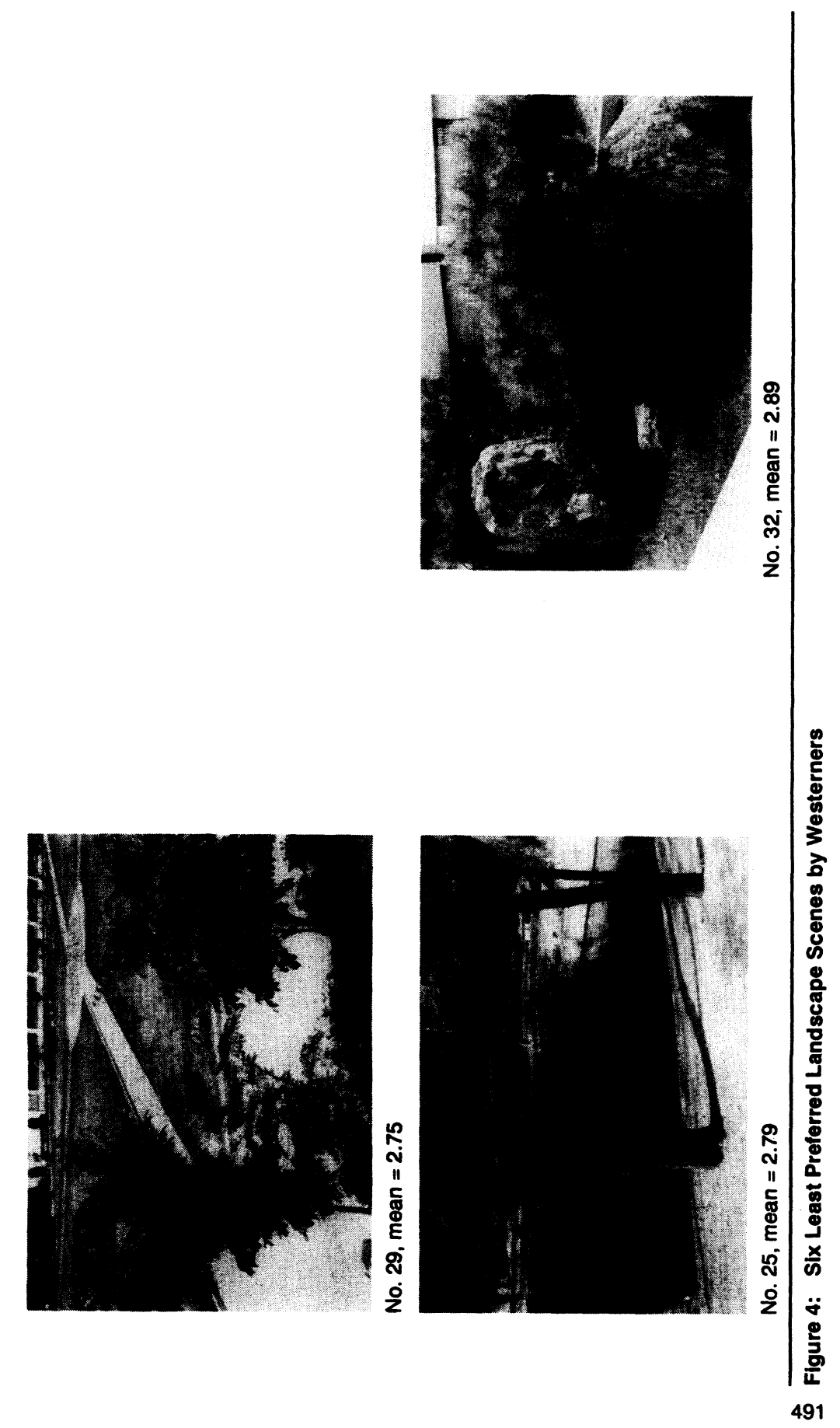


the difference between Western (3.14) and Korean (3.23) styles was not significant. The scenes included in the Japanese style showed greater variations in preference means, ranging from 2.73 to 4.48 , than for the other two styles. This suggests that not all Japanese landscapes are highly preferred and there are sharp differences in preferences depending on the spatial properties of the scenes. In contrast, the Western landscape style had a narrower range of mean scores (from 2.75 to 3.45 ) that suggests the Western sample's preferences for Western landscape style were not greatly influenced by other spatial properties of the landscape scenes. When comparisons are made between the American and European subgroups, it was found that Americans' preferences for Western landscape style (mean score $=3.25$ ) were higher than Europeans' preferences (mean score $=2.94$; the comparison was significantly different at $p<.05$ ).

\section{Relationship of Landscape Preferences to Landscape Element}

Significant differences were found in preferences for the different landscape elements $(F=5.63, p<.005)$. Water is the most preferred element (3.57) and rock (3.04) is the least preferred; falling in between was vegetation (3.35). The Western participants' preferences for landscape elements follow the same patterns as those of the Korean sample. In particular, the existence of water in the landscape plays a powerful role in enhancing preference regardless of cultural differences, which is consistent with other studies (Brush \& Shafer, 1975; Kaplan \& Kaplan, 1982; Shafer, Hamilton, \& Schmidt, 1969; Ulrich, 1981, 1983; Zube, Pitt, \& Anderson, 1975). Among the Western participants, the preference for water was higher for the Americans (mean score $=3.66$ ) than Europeans (mean score $=3.39$ ), which suggests the possibility of cultural influences on the preferences for water.

Observing the most and least preferred scenes representing the vegetation element, the following factors were judged influences on preference: (a) crooked forms of tree branches or trunks are more preferred than upright forms and (b) dense vegetation with some openings is more preferred than sparse 
or no vegetation. In addition, examinations of the most and least preferred scenes showing rock element suggest the following as factors related to preferences: (a) a single rock located in the scene as an ornamental or functional element is preferred to two or more rocks scattered in the scene, and (b) a rock surrounded by vegetation is preferred to rocks with a wall as background or other functional rocks without vegetation.

\section{Relationship of Landscape Preferences}

to Landscape Style and Element

In the case of Western tourists, as with the Korean respondents, the most preferred landscape style and landscape element combination was Japanese water (4.06) whereas Korean rock received the lowest preference score of 2.87 . It also turned out that there is no significant $(F=.506$, significance of $F=.732$ ) interaction effects between landscape style and elements. Among the water scenes, the pattern for the Korean sample was also repeated, with Korean water scenes preferred over Western water scenes. In the vegetation scenes, Japanese style was again first in preference. Analogous to Koreans' preferences, Westerners' preferences for rock turns out to be least preferred among landscape elements regardless of landscape style (see Table 2).

\section{CROSS-CULTURAL COMPARISON OF LANDSCAPE}

PREFERENCES BETWEEN KOREAN AND WESTERN SAMPLES

Comparison of preference mean score for both landscape style and element suggested that there is significant differences in main effects and no significant interaction effects between Korean and Western samples (see Table 3 for main effects).

\section{Characteristics of Landscape Preference Pattern}

Comparison of the preference ratings by the two samples shows both similarities and differences. In terms of overall preference pattern, two distinct differences can be found. First, 
TABLE 3

ANOVA of Preference Mean Score by

Landscape Style and Element Between Groups

\begin{tabular}{lrrrrr}
\hline Source of Variation & Sum of Squares & df & Mean Square & F & Significance of F \\
\hline Main effects & 12.687 & 6 & 2.115 & 16.146 & .000 \\
$\quad$ Landscape style & 3.303 & 2 & 1.652 & 12.612 & .000 \\
Landscape element & 4.952 & 3 & 1.651 & 12.604 & .000 \\
$\quad$ Groups & 4.822 & 1 & 4.822 & 36.817 & .000 \\
Explained & 12.687 & 6 & 2.115 & 16.146 & .000 \\
Residual & 9.560 & 73 & 0.131 & & \\
Total & 22.248 & 79 & 0.282 & & \\
\hline
\end{tabular}

NOTE: 80 cases were processed, 0 cases $(0.0 \mathrm{PCT})$ were missing. Due to empty cells or a singular matrix, higher order interactions have been suppressed.

Western tourists generally gave higher preference scores than Koreans (average 3.34 vs. 2.84). Second, even if one uses standardized scores (to eliminate the effect of the higher ratings by the Western tourists), the ratings by the two samples show distinct differences. For 11 scenes (see Figures 5 and 6), there is a difference of .7 or more (see Table 4). Of these scenes two (Numbers 2 and 4) were of Japanese rock and stone lantern, with the Koreans preferring one and the Western tourists preferring the other. In all the other cases, preferred scenes are for the other's cultural style, with five instances $(11,15,17,21$, and 29; see Figure 5) of Koreans having higher preferences for the Western style (including vegetation, water, and layout) and four instances (12, 19, 23, and 28; see Figure 6) of Westerners preferring Korean style and layout. Table 4 shows the comparisons of standard preference scores for each photo between groups.

Relationship of Landscape Preferences to Landscape Style

A closer examination of differences in preferences for landscape style between the two samples indicates that the Koreans prefer Western style to Korean style whereas Western tourists prefer Western style and Korean style alike (see Table 2 for 


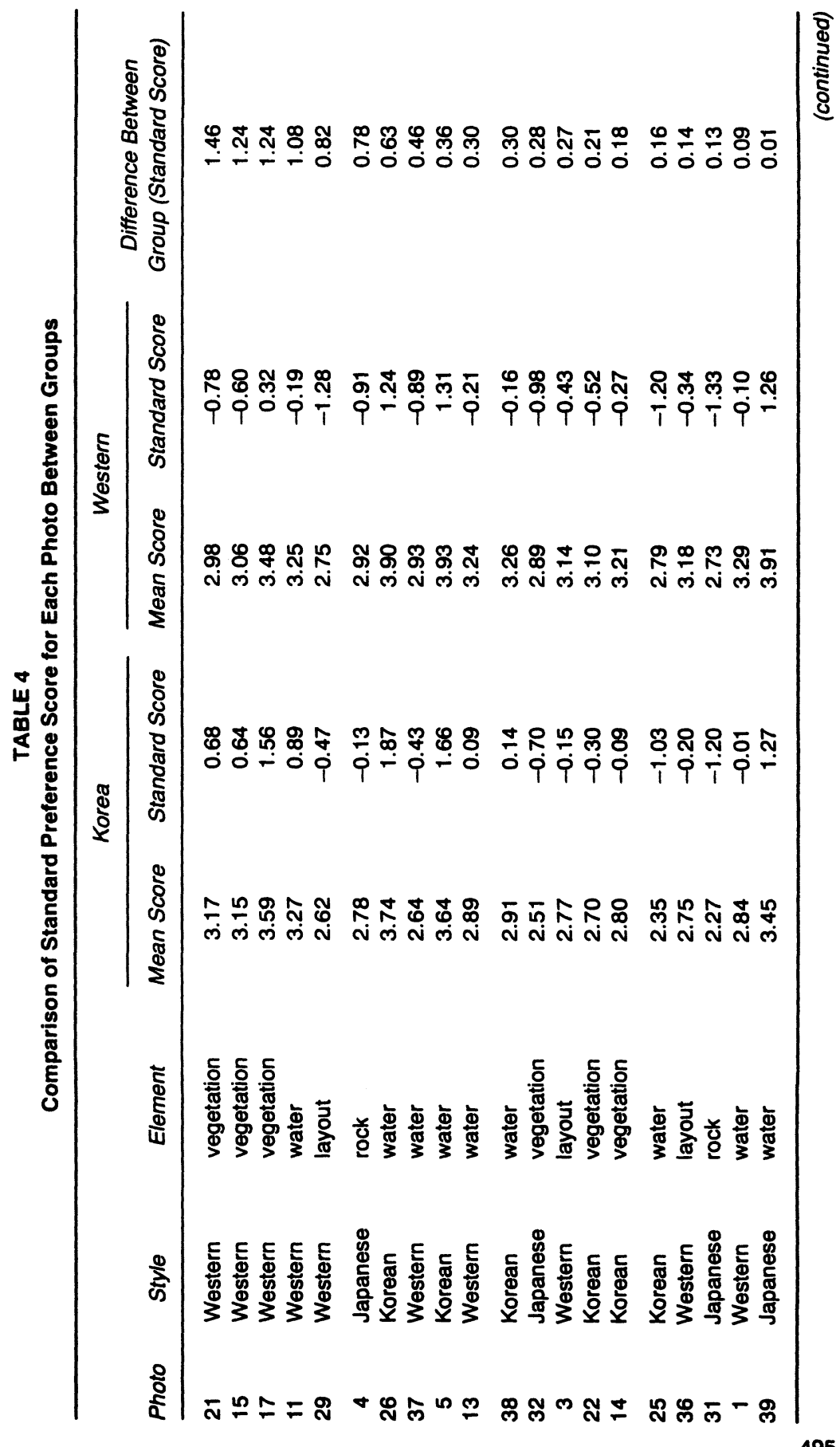




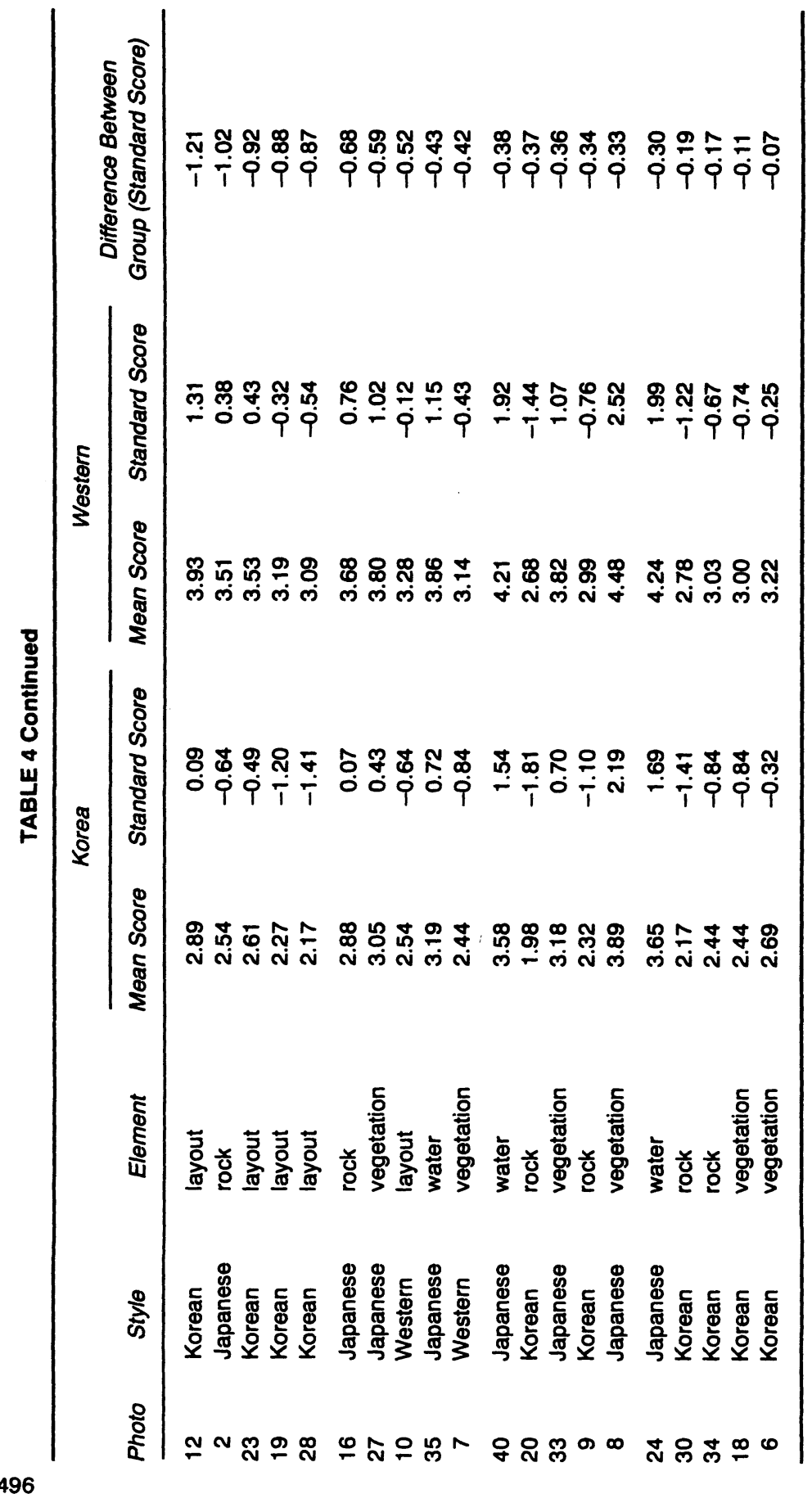


preference score and Table 3 for ANOVA). However, when differences in preference scores between Korean and Western style were compared between the two samples, it was found that Westerners' preference for Korean style is higher than Koreans' preference. ${ }^{1}$ In contrast to Western and Korean landscape styles, Japanese landscape style is most preferred by both samples, which was interpreted to indicate that Japanese landscape style is the most preferred style regardless of cultural differences.

\section{Relationship of Landscape Preferences to Landscape Element}

Comparison of the preferences for landscape elements between the two samples suggests that there are more similarities in the preferences for landscape elements between groups than differences. Regardless of cultural differences, water was the most preferred landscape element and rock was the least preferred element, with vegetation ranked in between (see Table 2 for comparison of preference mean score between groups and Table 3 for ANOVA). In contrast, the only difference between groups seems to be that an informal arrangement of vegetation is more preferred than formal and geometrical layout by the Korean sample whereas Western tourists have no salient preference patterns for the layout of vegetation.

\section{CONCLUSIONS}

The main purpose of this article is to compare the characteristics of preferences for a group of Korean citizens and Western tourists, with special emphasis on the general patterns of preference and the relationships of landscape preference to landscape styles and elements. The research results show both similarities and differences in the preferences of these crosscultural groups.

Westerners gave higher preference scores than Koreans did to all of the scenes included in this study. It seems that different criteria for preference judgments are among the main reasons 

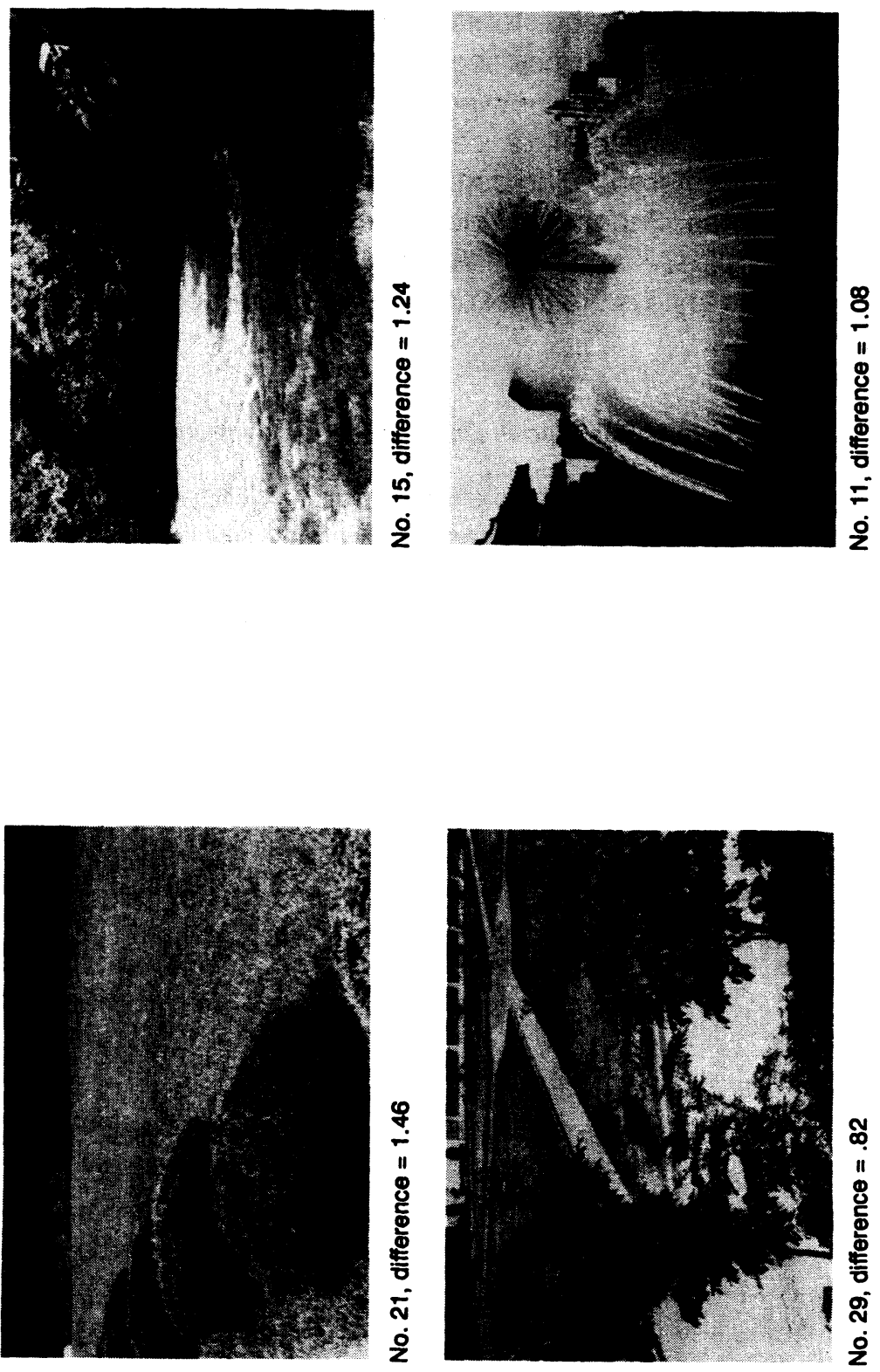


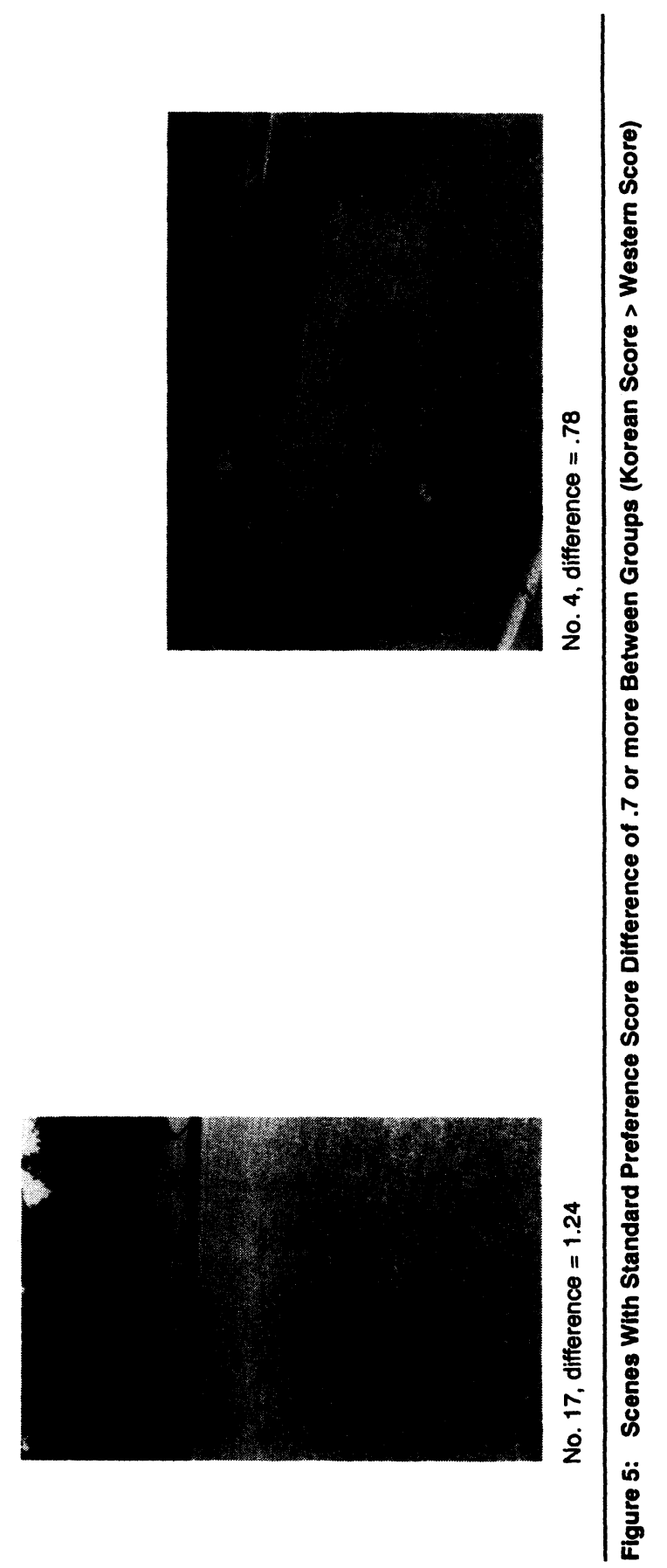



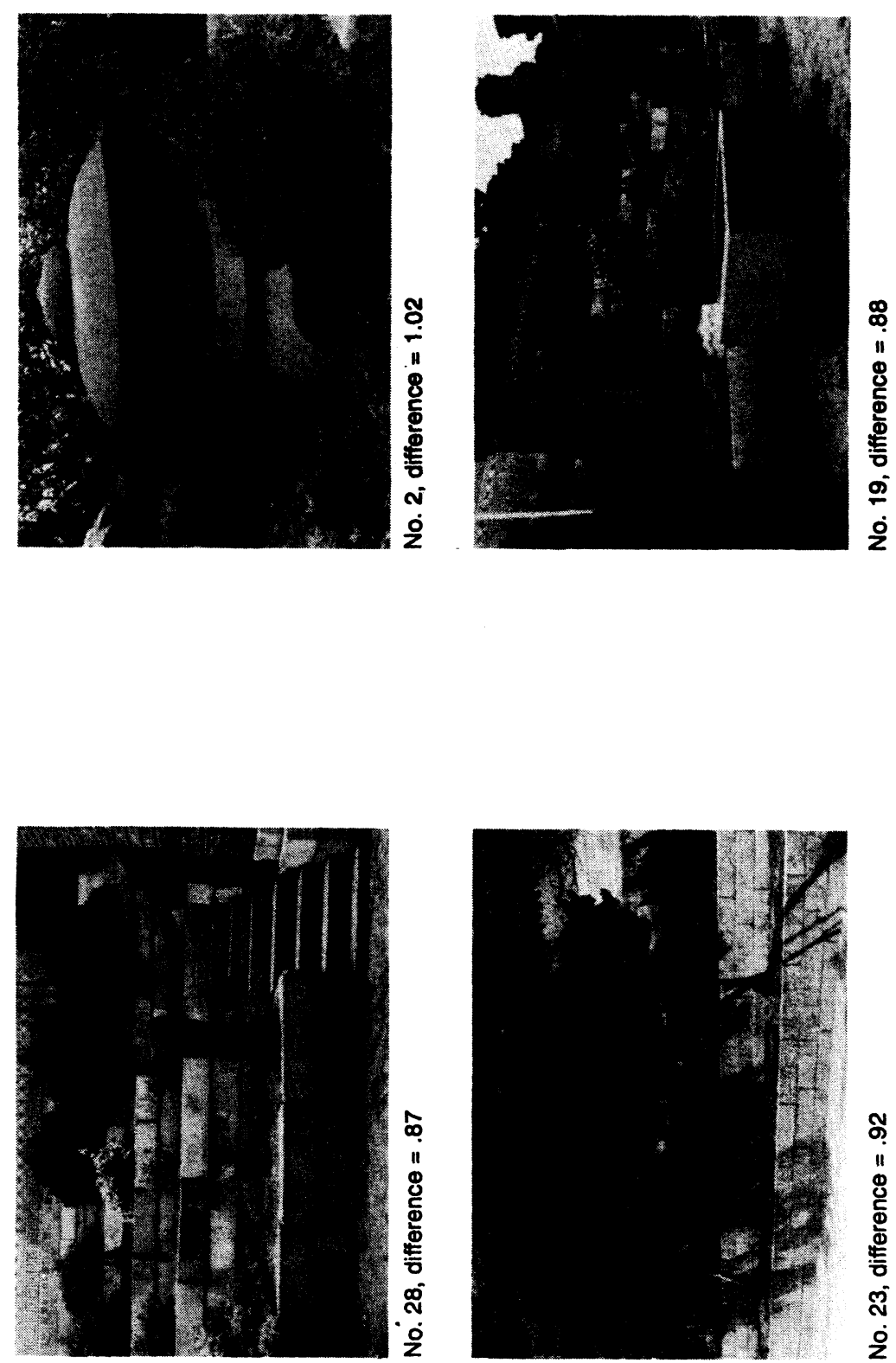


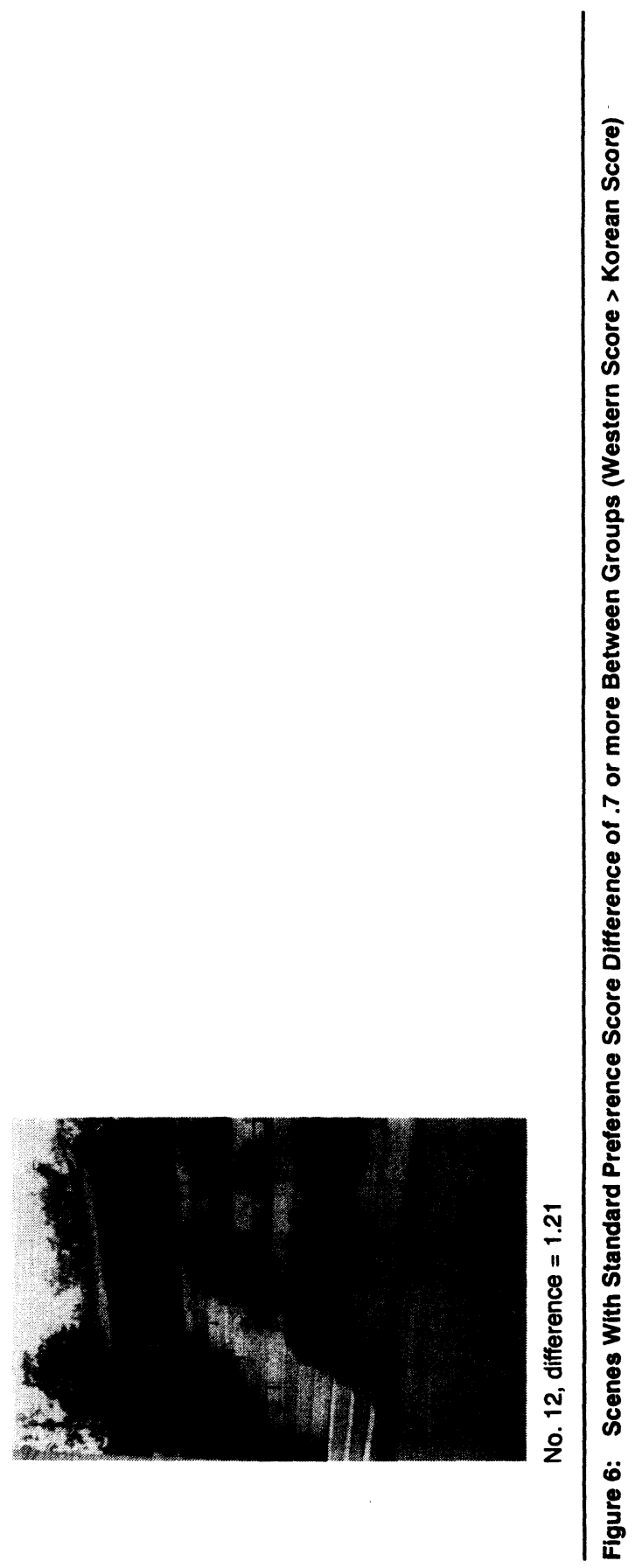


that Western tourists give higher preference scores than Koreans do in the overall pattern. However, more research must be done to find out the main reasons behind these differences in the preference scores between Koreans and Westerners. Regardless of the cultural differences, both Korean and Western tourists viewed Japanese landscape style as the most preferred. The research findings indicate that landscape style is recognized as an important factor in influencing preference regardless of cultural differences. Certain aspects that contributed to higher preference for Japanese style focused on water with reflections, dense vegetation, and nongeometric forms. Similar patterns also emerged when each viewed the other cultures' landscape style. For Koreans, Western landscape style is more preferred than their own Korean landscape style whereas Korean landscape style is more preferred by Western tourists. This finding implies that both the Korean group and Western tourists are inclined to prefer the landscape style which is not matched by their own cultural background.

The study also can make a number of suggestions concerning the landscape elements of water, vegetation, and rock. Water is the most preferred landscape element regardless of the cultural differences of the people. This is not a new finding and verifies a number of past studies. Not all types of water, however, equally embrace or enhance preference. Water with tree reflections, water surrounded by dense vegetation, and water in a natural setting seem to be more preferred than other types of water settings. This again is a true reflection of the Japanese landscape style of design. Rock and sculptured elements, on the other hand, were by far the least preferred landscape element among the three landscape elements regardless of cultural differences. Generally, it could be said that soft landscape materials like water or vegetation are more preferred than hard landscape materials like rock. The findings indicated that the preference for rock seemed to be affected by its relationship to soft landscape material. Used by itself, rock, a hard element, did not fair as well as it did if it was combined in a setting with a soft element, such as vegetation. Concerning the third element, vegetation, this was also highly preferred regardless 
of the cultural differences. The preference for vegetation differed, however, depending on the form, type of vegetation, and the relationship of vegetation with the other elements.

These findings become more significant when one looks at their relevance to environmental-design disciplines and how they can contribute to a better understanding of human behavior in the design environment. One design application relates to the arrangement of elements in space. The juxtaposition of water and vegetation was consistently more preferred. The combination of elements is one of the most powerful influencing factors of preference. The scenes showing rock with a background of vegetation are more preferred than scenes of rock without vegetation. This leads to a very interesting conclusion from a design perspective. It brings up the issue of soft landscape elements, which in this study appear to enhance preference, versus hard materials, which were not highly preferred. From a design perspective, it is useful to know that people preferred soft materials when choosing elements in the design arena. As was discussed in this study, people did not like singularly hard materials (in this case rock or hard pavement). The results of this study do indicate that scenes of soft landscapes, or those in which soft elements are used, in conjunction with hard elements are preferred over those in which hard elements singularly dominate the scene. The research also suggests that scenes that allowed visual access were more preferred than those in which visual access was lacking, blocked, or unclear. Thus visual access became an important factor in human environment preference. Taking visual access and coupling it with soft material and the combination of soft and hard materials, the designer has an interesting palette of elements to think about and use. This study confirmed many findings from other projects. There are landscape elements whose very presence is likely to raise or detract from preference. The existence of water in the landscape, as we have generally known, is found to enhance preference most.

This study yields several intriguing suggestions that could lead to future research. There are many commonalities in preference perception between cultural groups. The study clearly sug- 
gests that there is an abundance of commonalities in preference and perceptions but with some cultural variations between the Western and Korean viewers. The findings of this study also provide some clues to be used in judging this cultural influence. The findings indicate also that landscape style is a determinant of landscape preference for both Korean and Western groups. People are inclined to perceive landscape style as a coherent group. Japanese landscape style was most preferred and landscape style that is matched by one's own culture is generally, from our perspective, least preferred. This study, which we believe was the first investigation concerning the role of landscape style in landscape preference, dealt with only three different landscape styles. More research using a variety of landscape styles is needed to generalize the findings of this study. The findings that people prefer a landscape style not matched by their own cultural experiences suggest the possibility of cultural influences on landscape styles, and again, this is another area for future research. Additional research is also needed to investigate the possibility that foreign styles can be explained in part as responses to the novel or unfamiliar and in part by Kaplan's information content theory such as coherence, complexity, legibility, and mystery.

\section{NOTE}

1. Because Westerners' preference scores for the three landscape styles were consistently higher than Koreans' preference scores, direct comparison of Westerners' preference for Korean style with Koreans' preference was not so meaningful for judging whether or not Westerners' preference is higher than the Koreans'. Therefore, the differences in preference score among styles were compared between the two samples in order to eliminate effect of the higher ratings by Western tourists.

\section{REFERENCES}

Balling, J. D., \& Falk, J. H. (1982). Development of visual preference for natural environments. Environment and Behavior, 14, 5-28. 
Berlyne, D. E., Robbins, M. C., \& Thompson, R. (1974). A cross-cultural study of exploratory and verbal responses to visual patterns varying in complexity. In D. E. Berlyne (Ed.), Studies in the new experimental aesthetics: Steps toward an objective psychology of aesthetic appreciation (pp. 259-278). New York: Wiley.

Brush, R. O., \& Shafer, E. L., Jr. (1975). Application of a landscape preference model to land management. In E. H. Zube, R. O. Brush, \& J. G. Fabos (Eds.), Landscape assessment: Values, perceptions and resources (pp. 168-182). Stroudsburg: Dowden, Hutchinson \& Ross.

Chung, D.-O. (1982). A comparative study of traditional garden styles between Korean and Japan. Journal of Korean Traditional Garden Research Association, 1, 41-62.

Civco, D. S. (1979). Numerical modeling of eastern Connecticut's visual resources. Proceedings of Our National Landscape: A Conference on Applied Techniques for Analysis and Management of the Visual Resource (General Technical Report PSW-35, pp. 263-270). Berkeley, CA: USDA Forest Service, Pacific Southwest Forest and Range Experiment Station.

Gallagher, T. J. (1977). Visual preference for alternative natural landscapes. Unpublished doctoral dissertation. Ann Arbor: University of Michigan.

Graham, D. (1938). Chinese gardens. New York: Dodd, Mead.

Hammitt, W. E. (1978). Visual and user preference for a bog environment. Unpublished doctoral dissertation. Ann Arbor: University of Michigan.

Harada, J. (1956). Japanese gardens. London: The Studio.

Hayakawa, M. (1973). The garden art of Japan. New York: Weatherhill/Heibonsha.

Herzog, T. R., Kaplan, S., \& Kaplan, R. (1982). The prediction of preference for unfamiliar urban places. Population and Environment, 5, 43-59.

Hyams, E. (1971). A history of gardens and gardening. New York: Praeger.

Kaplan, R. (1979a). Visual resources and the public: An empirical approach. Proceedings of Our National Landscape: A Conference on Applied Techniques for Analysis and Management of the Visual Resource (General Technical Report PSW-35, pp. 209-216). Berkeley, CA: USDA Forest Service, Pacific Southwest Forest and Range Experiment Station.

Kaplan, R. (1979b). A methodology for simultaneously obtaining and sharing information. In T. C. Daniel, E. H. Zube, \& B. L. Driver (Eds.), Assessment of amenity resource values (General Technical Report, RM-68, pp. 58-66). USDA Forest Service, Rocky Mountain Forest and Range Experiment Station.

Kaplan, R. (1983). The role of nature in the urban context. In I. Altman \& J. F. Wohlwill (Eds.), Behavior and the Natural Environment (pp. 127-161). New York: Plenum.

Kaplan, R., \& Herbert, E. J. (1987). Cultural and sub-cultural comparisons in preferences for natural settings. Landscape and Urban Planning, 14, 281-293.

Kaplan, S., \& Kaplan, R. (1982). Cognition and Environment. New York: Praeger.

Kaplan, S., Kaplan, R., \& Wendt, J. S. (1972). Rated preference and complexity for natural and urban visual material. Perception and Psychophysics, 12, 354-356.

Küller, R. (1972). A semantic model for describing perceived environment (National Swedish Building Research Document D12). Stockholm: National Swedish Institute for Building Research.

Kwok, K. (1979). Semantic evaluation of perceived environment: A cross-cultural replication. Man-Environment System, 9, 243-249.

Lowenthal, D. (1968). The American scene. Geographical Review, 58, 61-88. 
Nasar, J. L. (1984). Visual preferences in urban street scenes; a cross-cultural comparison between Japan and the United States. Journal of Cross-Cultural Psychology, 15, 79-93.

Oldham, J. R. (1980). Gardens in time. Sydney: Lansdowne.

Palmer, J. F. (1978). An investigation of the conceptual classification of landscapes and its application to landscape planning issues. In S. Weidemann \& J. R. Anderson (Eds.), Priorities for environmental design and research part 1 (pp. 92-103). Washington, DC: Environmental Design Research Association.

Penning-Roswell, E. C. (1979). The social value of English landscapes. Proceedings of Our National Landscape (General Technical Report, PSW-35, pp. 249-255). Berkeley, CA: USDA Forest Service, Pacific Southwest Forest and Range Experiment Station.

Peterson, G., \& Neumann, E. (1969). Modeling and predicting human response to the visual recreation environment. Journal of Leisure Research, 1, 219-237.

Schroeder, N. W., \& Daniel, T. C. (1981). Progress in predicting the perceived scenic beauty of forest landscapes. Forest Science, 27, 71-80.

Shafer, E. L., Hamilton, J. F., \& Schmidt, E. A. (1969). Natural landscape preference: A predictive model. Journal of Leisure Research, 1, 1-19.

Shafer, E. L., \& Tooby, M. (1973). Landscape preferences: An international replication. Journal of Leisure Research, 5, 60-65.

Sonnenfeld, J. (1967). Environmental perception and adaptation level in the arctic. In D. Lowenthal (Ed.), Environmental perception and behavior. Chicago: University of Chicago, Department of Geography.

Tamura, T. (1935). Art of the landscape garden in Japan. Tokyo: Kokusai Bunka Shinkokai.

Thacker, C. (1979). The history of gardens. Berkeley: University of California Press.

Thayer, R. L., \& Atwood, B. G. (1978). Plants, complexity and pleasure in urban and suburban environments. Environmental Psychology and Nonverbal Behavior, 3, 67-76.

Tips, W.E.J., \& Savasdisara, T. (1986). Landscape preference evaluation and sociocultural background: A comparison among Asian countries. Journal of Environmental Management, 22, 113-124.

Tuan, Y-F. (1973). Visual blight: exercises in interpretation. In Visual blight in America (Commission on College Geography Resource Paper No. 23). Washington, DC: Association of American Geographers.

Tung, C. (1940). Chinese gardens: Contrast; designs. In H. Inn (Ed.), Chinese houses and gardens. Honolulu: Fong Inn's Ltd.

Ulich, R. S. (1977). Visual landscape preference: A model and application. ManEnvironment Systems, 7, 279-293.

Ulrich, R. S. (1981). Natural versus urban scenes: Some psychophysiological effects. Environment and Behavior, 13, 523-556.

Ulich, R. S. (1983). Aesthetic and affective response to natural environment. In I. Altman and J. F. Wohlwill (Eds.), Behavior and the Natural Environment (pp. 85-125). New York: Plenum.

Vining, J., Daniel, T. C., \& Schroeder, H. W. (1984). Predicting scenic values in forested residential landscapes. Journal of Leisure Research, 16, 124-135.

Yoon, K.-B. (1983). The characteristics of Korean garden (Korean garden series, 9). Weekly Chosun, 1 (March), 90. 
Zube, E. H. (1984). Themes in landscape assessment theory. Landscape Journal, 3 , 104-110.

Zube, E. H., \& Mills, L. V., Jr. (1976). Cross-cultural explorations in landscape perception. In E. H. Zube (Ed.), Studies in landscape perception (pp. 167-174). Amherst: University of Massachusetts, Institute for Man and Environment.

Zube, E. H., \& Pitt, D. G. (1981). Cross-cultural perceptions of scenic and heritage landscapes. Landscape Planning, 8, 69-87.

Zube, E. H., Pitt, D. G., \& Anderson, T. W. (1975). Perception and prediction of scenic resource values of the Northeast. In E. H. Zube, R. O. Brush, \& J. G. Fabos (Eds.), Landscape assessment (pp. 151-167). Stroudsburg: Dowden, Hutchinson \& Ross. 